
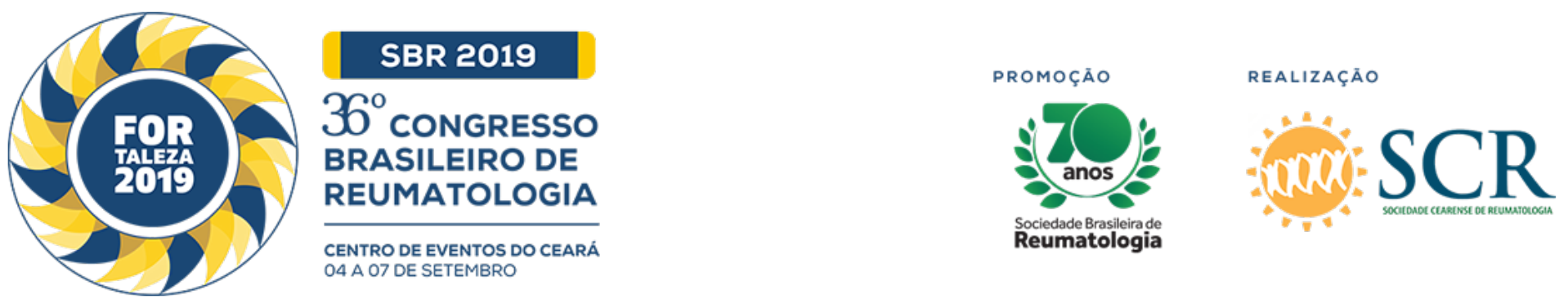

\title{
EPIDEMIOLOGICAL PROFILE, HEALTH COSTS AND HOSPITAL MORTALITY DUE TO SYSTEMIC DISEASES OF THE CONNECTIVE TISSUE IN THE STATE OF CEARA IN THE PERIOD 2008-2018: RESULTS OF A STUDY GROUP IN RHEUMATOLOGY OF BRASILIA.
}

João Carlos Geber Júnior (Departamento de Clínica Médica - Hospital Alvorada Brasília, Brasília, DF, Brasil), Natan Teixeira da Silva (Faculdade de Medicina - Escola Superior de Ciências da Saúde, Brasília, DF, Brasil), Victor Hudson de Lacerda Borges (Faculdade de Medicina - Escola Superior de Ciências da Saúde, Brasília, DF, Brasil), Rafaela Moreira de Carvalho (Faculdade de Medicina - Centro Universitário de Brasília, Brasília, DF, Brasil), Ediana Paula Tudrei Pantoja (Faculdade de Medicina - Escola Superior de

Ciências da Saúde, Brasília, DF, Brasil), Ana Paula Monteiro Gomides Reis (Faculdade de Medicina -

Centro Universitário de Brasília, Brasília, DF, Brasil), Viviane Cristina Uliana Peterle (Faculdade de Medicina - Escola Superior de Ciências da Saúde, Brasília, DF, Brasil)

\section{BACKGROUND}

Systemic Connective Tissue Diseases (SCTD) are important cause not only of pain, physical disability, decreased quality of life and years of life lost, but of high costs with hospitalizations and medications per patient. Recent studies have shown that the proportional economic impact on SCTD can often be greater than cardiovascular and oncologic. With evolution and improvement in the treatment of SCTD, the prevalence and, consequently, the costs with great impact in public and private health systems have increased. The objective of the present study is to describe the epidemiological profile, costs recorded and the hospital mortality coefficient by SCTD in the state of Ceará.

\section{MATERIALS AND METHODS}

This is a descriptive, ecological study, based on data obtained from the Hospital Information System of the Unified Health System (SIH-SUS). Data from hospital morbidity related to diseases of the Osteomuscular System and Connective Tissue - Chapter XIII of the ICD-10 correspond to the M30-M36 codes of patients aged between 20 and 80 years in the period 2008-2018 in the state of Ceará. Variables analyzed: number of hospitalizations, age group, sex, mean and total value by hospitalization, mean length of stay, deaths. The hospital mortality coefficient was obtained by the ratio of the number of deaths by SCTD by the number of total hospitalizations for all causes.

\section{RESULTS}

There were registered 1,909 hospitalizations, accounting for $9.6 \%$ of hospitalizations for SCTD in the Northeast Region, $4 \%$ of hospitalizations of the Diseases of the Osteomuscular and Connective Tissue System and $0.05 \%$ of all hospitalizations due to all causes in the period accounting for a total amount of $R \$ 1.65$ million. The mean value for hospitalization was $R \$ 868.89$, with an average stay of hospitalization of 12.2 days and a record of 50 deaths. There was a general distribution without singularities in both sexes by age groups, standing out a woman / man ratio of 2,1:1. The total expenditure with admission to the female was $141 \%$ higher than the male. The hospital mortality rate in the period was 1.3 deaths per 100,000 admissions.

\section{CONCLUSION}

Despite the limitations related to notifications, it is possible to quantify data from health information systems, transforming them into information that can support the SUS management process. The analysis shows agreement with other epidemiological studies about the profile of this group of diseases, such as predominance among women, especially lupus. 